\title{
La maestra como directora escolar: gestión pedagógica y espacio público en Chile (1900-1927) ${ }^{1}$
}

The female teacher as a principal: pedagogical managing and public space

Leyla Torres-Bravo

Universidad de Talca, Chile

ltorres@utalca.cl

\section{Resumen}

Este trabajo se propone describir y analizar la acción directiva de maestras en centros escolares femeninos, en términos de hacer constar tanto el sentido pedagógico como el liderazgo adquirido en sus funciones. En tal sentido, se toma como referente el libro Actividades femeninas en Chile, publicado en 1928, ya que se centra de forma directa, en algunas de sus partes, en el ámbito educativo. Así, mediante el análisis de discurso, se explora la formación de niñas y jóvenes durante el período, desde la cual se aprecia el rol cumplido por las directoras. De esta forma, se constata que los efectos de su quehacer directivo están presentes y son, por cierto, esenciales en su profundo compromiso ético-social, en las actividades culturales y asociativas con países latinoamericanos, en el interés por el perfeccionamiento docente en Europa y en los Estados Unidos, en las experiencias situadas en la Escuela Nueva y en el nacionalismo e higienismo, entre otros aspectos.

Palabras clave: Formación de niñas y jóvenes, Acción directiva, Maestras, Comunidad escolar.

\section{Abstract}

This paper is intended the describe and analyze the managing action by women teachers at female schools, to show both the pedagogical sense and the leadership got by carrying out their functions. Thus, the reference is the book Actividades femeninas en Chile, published in 1928 , since it is focused, in a direct way, in some of its sections, on education. Thereby, by, means of speech analysis, the present paper explores the academic formation for girls and

\footnotetext{
${ }^{1}$ Recibido: 30/01/2021 Evaluado: 04/03/2021 Aceptado: 02/04/2021
} 
young women during the period, in which the role played by female principals can be noted. In this way, it is verified that the effects of their managing activities are present and essential in their deep ethical and social commitment, in the cultural and associative activities with Latin American countries, in the wish for teaching perfection in Europa and the United States, in the experiences based in Progressive Education, and in nationalism and hygienism, among other points.

Keywords: Education and training of children and young women, Directive action, Female teachers, School communities.

\section{Introducción}

Rastrear el aporte de la acción femenina en el sistema escolar durante las dos primeras décadas del siglo XX, requiere, en primer lugar, atender el modo con el que las mujeres tuvieron cabida en la función docente. Por consiguiente, resulta interesante también hacer notar cómo su presencia dio paso, un poco más tarde, a su quehacer directivo tanto en escuelas como en liceos de niñas. De ahí que sea importante situar sus intereses y contribuciones, con el objeto de dilucidar el sentido socioeducativo que tuvo su gestión escolar en la comunidad.

A partir de una mirada histórica y desde la perspectiva de género, es pertinente comprender la experiencia en el cargo de algunas directoras como forma de poner en evidencia su inserción en el espacio educativo público, distinguiendo mediante ello sus avances y rechazos. Todo esto conlleva, al mismo tiempo, la construcción de aquella identidad profesional que se instala como un prototipo femenino, y desde la cual es que se hace factible encontrar más luces acerca de la manera en que se materializa su función directiva. Al respecto, conviene tener presente el marco en el que emerge y se sostiene el estereotipo de maestra subordinada. En palabras de Little (1983-84), esta es una categoría que sirvió, en su momento, para normalizar una posición ideológica que dejaba fuera a las maestras estadounidenses del puesto directivo, especialmente en los años veinte. En cualquier caso, tal situación se hará igualmente extensiva a las vivencias escolares de maestras y directoras en Europa e Iberoamérica.

Esta indagación, en base a lo expresado, intenta llevar a cabo una aproximación históricoeducativa respecto a las mujeres que, en Chile, se dedicaron a la tarea de dirigir centros escolares femeninos primarios y secundarios de reciente aparición en el periodo señalado. Desde allí, se plantea que es muy oportuno tomar en cuenta no solo los diversos debates públicos que rodean la formación femenina, sino que también resulta fundamental incluir y hacer hincapié en aspectos claves como son: la identidad profesional de las maestras y directoras, junto con su liderazgo y gestión pedagógica. Pero, además, importa identificar el clima y la cultura escolar que circunscriben sus funciones. A la luz de todo esto, se hace posible extrapolar estas categorías actuales hacia las acciones materializadas por las directoras.

En este artículo, en suma, se exploran tanto las particularidades como las dinámicas pedagógicas ejercidas por directoras en escuelas y liceos de niñas, las que, en su día, fueron retratadas en partes del libro Actividades femeninas en Chile (1928). Desde esta perspectiva

No 9, 2021. Página $\mid 130$ 
de referencia, se orienta el análisis del discurso tocante al sentido y alcance que encierra la gestión directiva y la formación femenina hace ya casi un siglo atrás. ${ }^{2}$

\section{Las primeras escuelas y liceos femeninos en Chile. La formación de maestras y la dirección escolar en estos (1890-1927)}

Como esbozamos con antelación, las escuelas y liceos femeninos empezaron a ser gestionados por las maestras, las que, primero, consolidaron su presencia y práctica pedagógica en el sistema escolar. Desde los primeros años del siglo XIX, su formación académica tuvo un avance irregular en el país. De hecho, si efectuamos una rápida revisión panorámica de la época se observa con bastante claridad la creciente y, a la vez, sostenida feminización del cuerpo docente. Al respecto, Núñez Prieto (2007) expresa que, con la aparición de las preceptoras, la formación inicial de maestras alcanzó un notable avance y refuerzo entre los años 1840 y 1891. Empero, tanto su incorporación docente como su labor directiva fue desplegada con escasa celeridad. Lo dicho deja entrever la compleja situación que, en su momento, atravesó la integración masiva de niñas y jóvenes en la educación formal. Con ello, asimismo, queda de manifiesto la carencia de centros educativos para mujeres. A lo que se agrega la enorme dificultad para crear nuevas escuelas y liceos financiados por el Estado. Todo esto, igualmente, nos dice el autor, redundaría en la baja existencia de maestras tituladas.

Hacia fines del siglo XIX, se evidencia un muy lento comienzo en la fundación de escuelas y liceos femeninos fiscales. No obstante, esto se transformó en un asunto de creciente interés para intelectuales y padres, quienes se abocaron a conseguir un espacio educativo para las mujeres. Dentro de este marco y mediante una iniciativa privada, se fundaron los primeros liceos de niñas en Chile. Será, entonces, la Asociación de Padres de Familia para la Instrucción de la Mujer la entidad encargada de su creación. Nótese, por cierto, que muchos de sus integrantes eran masones, quienes disponían de un alto nivel de vida y una posición social privilegiada. Es, conveniente, aclarar también que los recién inaugurados liceos femeninos utilizaron la subvención del Estado. Es así como a partir de tal forma de asociación, se pudo, en primera instancia, hacer realidad la fundación de liceos de niñas en las ciudades de Copiapó, La Serena, Valparaíso y Concepción (Labarca, 1928; Ojeda Laso, 1993; Sánchez, 2006; Vicuña Domínguez, 2012).

La educación secundaria femenina y su avance en Chile, aparece tempranamente retratada por la educadora chilena Amanda Labarca, en el libro que revisamos aquí bajo el título de Actividades femeninas en Chile (1928). En su escrito, advierte el hecho de que estos liceos de niñas se crearan en ciudades de provincia, como una respuesta liberal acogida por los círculos sociales de los nuevos adinerados de la minería y del comercio. Pero, a su vez, ello trajo como resultado la creación de liceos femeninos en Santiago. Respecto a esto, se puede hacer notar que ante el exacerbado y arraigado centralismo que todavía opera en el país, en

\footnotetext{
${ }^{2}$ Este artículo se adscribe al proyecto de investigación I+D: "Espacios de conocimiento, cultura y agencia femeninas en el mundo Moderno y Contemporáneo (siglos XV-XX), PGC2018-097445-B-C21, subproyecto del Coordinado, "Género, cultura y subjetividad: más allá de las políticas del conocimiento (siglos XV-XX)", Ministerio de Ciencia, Innovación y Universidades, España.
} 
tal momento, la capital se vio superada. Así pues, en Santiago, se hará realidad esta iniciativa liberal, provincial y de gobierno, en virtud de la aprobación del proyecto denominado programas para un liceo fiscal de señoritas. Por medio de este, se creó el "Instituto de Señoritas", asumiendo en el cargo de directora la maestra alemana Juana Gremler Lorenz.

La configuración de la formación de maestras de escuelas y liceos de niñas se concentrará, en sus inicios, en las religiosas del Sagrado Corazón. Esto, sin duda, marca un principio y un asiduo avance en la preparación de maestras. De ahí que rápidamente se convierta en un punto de referencia para las nuevas formadoras. A pesar de ello y, anteponiendo los nuevos requerimientos escolares, la emergente política educativa dará un paso definitivo hacia la ampliación paulatina de una emblemática formación inicial de maestras, la que será, en definitiva, liderada por las Escuelas Normales y por el Instituto Pedagógico.

\section{Actividades femeninas en Chile (1877-1927)}

Este libro surge como un compendio de las actividades conmemorativas del Cincuentenario del Decreto Amunátegui (1877). Es, por tanto, lógico indicar que este último se instituyó en un documento de especial relevancia para la educación chilena. Este fue promulgado en el año 1877, siendo su artífice el Sr. Miguel Luis Amunátegui, Ministro de Justicia, Culto e Instrucción Pública. Ciertamente, cabe destacar que el decreto fue el resultado de un intenso debate público acerca de la educación de mujeres. Por lo que contó con el apoyo activo de intelectuales como Antonia Tarragó e Isabel Lebrún.

El contenido normativo del Decreto Amunátegui oficializa la formación universitaria femenina en Chile. En tal sentido, valida los exámenes y establece mediante ello, la posibilidad para la mujer de obtener un título académico de carácter científico. Otra de sus facilidades pone especial énfasis en el futuro de las tituladas, pues especifica que estas tendrían la oportunidad de administrar su propia subsistencia.

De esta forma, el Decreto Amunátegui pasó a constituirse en un hito para la incorporación de la mujer en el campo intelectual y laboral del país. Ante este panorama y debido a su alto significado se dispuso, en 1927, de todo un entorno y de una oficialidad conmemorativa para festejar su Cincuentenario con apoyo gubernamental. En tal sentido, cabe precisar la participación que tuvieron el Presidente de la República, Sr. Carlos Ibáñez del Campo y el Presidente de la Sociedad Nacional de Profesores, Sr. Pedro Aguirre Cerda.

Un asunto que, sin duda, merece una especial atención aquí es el aporte específico realizado por un grupo de mujeres que destacó en la organización, desarrollo y repercusión del evento. Todas ellas, pertenecían a la élite nacional o a la clase media que recién y tímidamente aparecía en el país. Como hace notar Bazored (2006), a partir de 1920 y en virtud del crecimiento económico y la acción gubernamental, es que la clase media emerge en la escena nacional. De manera que, como es sabido, las mujeres de las clases populares como obreras, campesinas y trabajadoras de hogares particulares y propios, obviamente fueron las relegadas y olvidadas en la conmemoración. 
Perfilado en tal contexto, el libro Actividades femeninas en Chile (1928), actúo como un verdadero referente en la exhibición pública del aporte efectuado por connotadas profesionales e intelectuales chilenas y extranjeras residentes en el país.

Al revisar el texto, se aprecia en su primera parte y, bajo el título de "Fiestas conmemorativas", el escrito de la Profesora Normalista y Profesora de Estado, María González Donoso. En este, por un lado, detalla los antecedentes históricos del Decreto Amunátegui. Y, por otro, atestigua y pone de relieve su trascendencia educativa para las mujeres. Será, en su última parte, donde la autora haga referencia a la estructura del Comité organizador del evento. Este fue integrado solo por mujeres.

Hay que destacar que el Comité tuvo como objetivo mostrar el aporte femenino desarrollado en Chile, en el periodo entre el Decreto Amunátegui y el año de su cincuentenario. Así pues, se dio a la tarea de averiguar y conectar en detalle aquellas actividades femeninas que, hasta el momento, se habían reflejado sobre el progreso económico, social y cultural del país. Para esto, el Comité organizó trece secciones vinculadas con las acciones femeninas en distintas áreas. No obstante, fue el ámbito educativo el que obtuvo una mayor representación. Ello, porque, evidentemente, se constata que su función educativa estaba asociada en plenitud tanto con el cuidado como con la enseñanza de infantes. Las secciones educativas fueron siete y se organizaron en los siguientes bloques, a saber: a) Educación Sanitaria, b) Educación Primaria Fiscal, c) Educación Secundaria Fiscal, d) Educación Particular, e) Educación Normal Fiscal, f) Educación Normal Particular y g) Educación Profesional.

Al finalizar este primer capítulo, se menciona que las actividades iniciales del Cincuentenario se efectuaron en Santiago con el beneplácito y la participación de las autoridades de gobierno. Empero, en sentido amplio, las fiestas conmemorativas tuvieron una respuesta positiva y activa desde las provincias. Para concluir, resulta oportuno hacer notar aquí las palabras de la profesora González Donoso, en relación a las mujeres y a la celebración del evento: "No hubo un solo detalle que no contribuyera a hacer de cada uno de los actos conmemorativos del Cincuentenario Amunátegui, un triunfo del esfuerzo y de la cultura femenina" (p. 23).

Considérese estas observaciones como descripción preliminar del contexto histórico y cultural en que se enmarca el libro Actividades femeninas en Chile (1877-1927). Ahora bien, el capítulo resulta, a su vez, crucial para atestiguar los inicios y progresos históricos de la participación femenina en la educación. En tal sentido, el capítulo III es el que merece especial atención en cuanto a lo previamente expresado. Aparece en él, en primer lugar, un breve compendio histórico del avance paulatino conseguido por la educación primaria femenina. Lo escribe la profesora de Estado y normalista, Belarmina Puebla, quien en dicho texto expresa una visión basada en la tarea educativa de la mujer en el hogar y en la contribución de su educación para respaldar la prosperidad nacional.

Para dar alcance a su revisión, la maestra trata de extraer el sentido y los modos de configuración que operan en la instrucción femenina, teniendo en cuenta el devenir histórico del país. Por consiguiente, su revisión hace alusión a los hitos y procesos claves que dan cuenta del ingreso y permanencia de la mujer en la educación formal, en el transcurso de la colonia, la independencia y la república. Al mismo tiempo, se realza tanto el valor como el efecto que produjo en la educación de las mujeres, la promulgación de la ley orgánica de 
Instrucción Primaria en 1866. Mención especial ocupa el aumento de la cobertura escolar femenina y la creación de escuelas alternadas. Estas últimas serán sustituidas prontamente por las escuelas mixtas o coeducativas, las que, en rigor, comenzarán a ser dirigidas por maestras de acuerdo con el decreto promulgado en 1881. Se dará, de igual forma, notoriedad a la reforma pedagógica de 1883. Lo que se tradujo, por un lado, en la puesta en funcionamiento de la regulación de los planes de estudio en las escuelas elementales y las escuelas superiores femeninas. Y, por otro lado, se instaura la misión de visitadoras especiales con el propósito de difundir los cursos orientados a las labores femeninas reguladas en la época. Concluirá esta revisión con la reciente y no menos importante promulgación de la ley de Instrucción Primaria Obligatoria de 1920. Agregando también la fundación de las escuelas vocacionales. En el resto del capítulo, será incluida una recopilación de datos cuantitativos que informan sobre el estado de avance de la enseñanza primaria hasta 1927.

\section{Maestras en la función directiva: revisión de su liderazgo y su gestión educativa en escuelas y liceos fiscales en Chile}

Como hemos anticipado, en el libro Actividades femeninas en Chile (1928), nos interesa verificar el modo con el que las directoras contrajeron sus tareas de liderazgo y de gestión pedagógica. Además de la manera con la que comenzaron a potenciar su identidad profesional en la dirección escolar. Por otra parte, a raíz de esto, se hace oportuno constatar cómo las directoras se incumbieron en la cultura y en el clima de la escuela. Todo ello, con el objeto de comprender si hubo o no cercanía e impacto en el profesorado y en las educandas, así como en la comunidad vecinal.

De acuerdo con lo antes mencionado, hemos procedido a revisar y analizar tanto los datos como las imágenes expuestas en su capítulo III: 'Educación'. En concreto, porque es la parte del libro que contiene la información necesaria para alcanzar el objetivo de esta indagación histórica-educativa y de género.

Para tal efecto, se tomó como muestra el capítulo antes mencionado. Luego, se procedió a establecer las categorías apriorísticas (ver Tabla 1), en función de las tipologías asociadas con el liderazgo directivo y con la gestión pedagógica de centros escolares. Tales datos fueron extraídos de artículos académicos, los cuales fueron seleccionados por su pertinencia con el tema en las áreas de la gestión y del liderazgo educativo. Pero, a su vez, debemos clarificar que sus aspectos fueron modificados intencionalmente con el objeto de implementar una mejor comprensión del fenómeno de estudio que hemos declarado.

En segunda instancia, se trabajó con la búsqueda de categorías emergentes mediante la lectura minuciosa del contenido temático que, en todo el capítulo, estaba referido a la educación femenina en Chile entre 1877 y 1927. Así pues, se creó un marco de referencia analítico en el cual fueron seleccionadas solamente las escuelas y liceos fiscales. Esta decisión tuvo que ver con el enorme impacto y significado recibido por la educación femenina. Sobre todo, por las posibilidades de ascenso social de aquellos sectores cuya búsqueda constante por encontrar mejores perspectivas de vida, se ha visto relegada y amenazada por la discriminación, el racismo y la falta de una distribución más equitativa de 
la riqueza, entre otros aspectos. Esta cuestión es indiscutible, asimismo, para la situación histórica de las mujeres porque nos revela el retraso en sus oportunidades de estudio y en las opciones de conseguir un trabajo remunerado.

Tabla 1. Categorías apriorísticas del estudio

\begin{tabular}{|c|c|}
\hline $\begin{array}{l}\text { Estilos de liderazgo educativo } \text { y } \\
\text { desarrollo en directoras }\end{array}$ & $\begin{array}{l}\text { Representación social del liderazgo en } \\
\text { acción }\end{array}$ \\
\hline $\begin{array}{l}\text { - Alto compromiso educativo con la } \\
\text { comunidad escolar }\end{array}$ & $\begin{array}{l}\text { Vinculación emocional y laboral tanto con } \\
\text { docentes y estudiantes como con padres y } \\
\text { comunidad }\end{array}$ \\
\hline $\begin{array}{l}\text { - Liderazgo facilitador y aprecio por } \\
\text { los demás }\end{array}$ & $\begin{array}{l}\text { Respaldo y reconocimiento público del aporte } \\
\text { de cada uno de los miembros de la comunidad } \\
\text { educativa }\end{array}$ \\
\hline $\begin{array}{l}\text { Interacción efectiva y colaborativa } \\
\text { con la comunidad escolar }\end{array}$ & $\begin{array}{l}\text { Comunicación abierta con otros a través de } \\
\text { espacios de trabajo conjunto con el personal } \\
\text { docente y administrativo, así como con los } \\
\text { estudiantes y la comunidad }\end{array}$ \\
\hline $\begin{array}{l}\text { Fomento de la autoestima, la } \\
\text { participación activa y el intercambio } \\
\text { de poder e información }\end{array}$ & $\begin{array}{llrr}\text { Apoyo a los éxitos personales } & \text { y } \\
\text { académicos/laborales. Posibilidad } & \text { de } \\
\text { armonizar las metas personales } & \text { y } \\
\text { organizacionales } & & & \end{array}$ \\
\hline $\begin{array}{l}\text { - Influencia en la toma de decisiones } \\
\text { pedagógicas del profesorado a favor } \\
\text { de la diversificación de métodos de } \\
\text { enseñanza-aprendizaje }\end{array}$ & $\begin{array}{l}\text { Espacios de reflexión pedagógica y de } \\
\text { perfeccionamiento docente en contextos } \\
\text { formales e informales }\end{array}$ \\
\hline $\begin{array}{l}\text { - Poner énfasis en el desarrollo del } \\
\text { currículo escolar }\end{array}$ & $\begin{array}{l}\text { Responsabilidad personal ante la consecución } \\
\text { de metas de aprendizaje del estudiantado } \\
\text { compartidas por la comunidad }\end{array}$ \\
\hline
\end{tabular}

Fuente: modificación propia en base a lo expuesto en Fennell (2008) y Growe y Montgomery (2000).

En última instancia, resulta inevitable destacar que las categorías emergentes (ver Tabla 2) se constituyeron con los datos expuestos por las distintas autoras en el capítulo. Su nivel de frecuencia en el texto determinó su incorporación y su grado de significancia para con la función directiva y para con las actividades escolares dispuestas en su contexto. Asimismo, tenemos que tener en cuenta la subjetividad y el enaltecimiento que se hace de ciertos eventos. Por lo mismo, hay que decir que el libro tiene como finalidad resaltar el aporte femenino en el país y, conforme a ello, es que se estipulan sus apreciaciones. En suma, se hace imprescindible afirmar que resulta indudable todo el esfuerzo y la riqueza de datos aportados en este libro. 
Tabla 2. Categorías emergentes del estudio

\begin{tabular}{|c|c|}
\hline Categorías emergentes \\
\hline - & Relaciones de apertura de la escuela con la comunidad: padres/madres/tutores/vecinos \\
\hline - & Cursos especiales impartidos para niñas y jóvenes a iniciativa de las directoras y/o \\
& maestras \\
\hline - & Iniciativas y esfuerzo de maestras y/o directoras en el mejoramiento del bienestar escolar \\
\hline - & Funciones directivas y acciones pedagógicas \\
\hline - & Campañas escolares desplegadas en la escuela o liceo \\
\hline - & Participación activa o pasiva de padres y vecinos \\
\hline - & Incentivos a la formación valórica de niñas y jóvenes \\
\hline - & Acciones comunitarias de la escuela en el vecindario o en la ciudad \\
\hline - & Actividades de confraternidad con otros países \\
\hline
\end{tabular}

Fuente: elaboración propia.

Como se precisa más arriba, se obtuvieron once categorías emergentes que tienen relación directa con las actividades declaradas tanto por las escuelas como por los liceos femeninos fiscales. Luego de ello, se realizó el correspondiente análisis cualitativo del material, el cual se focalizó tanto en la perspectiva de género como en la mirada histórica-educativa de la función escolar de directoras y del cuerpo docente en este estudio de caso. Para esta segunda etapa, fueron utilizadas las categorías apriorísticas seleccionadas de acuerdo con el criterio de estilos de liderazgo escolar y su desarrollo en directoras.

Resulta importante reparar en las características de las escuelas y liceos femeninos físcales que son parte de la muestra. En efecto, se hace mención, a lo largo del capítulo, de cinco escuelas normales superiores de niñas y una escuela mixta, seis liceos de niñas y un liceo de aplicación femenino.

Cabe decir, además, que tales centros escolares femeninos contaban con la tipificación vigente en 1927. Es, igualmente, de interés puntualizar la existencia de un orden numeral asignado para identificar con facilidad a todas las escuelas y liceos fiscales del país. Este criterio, por supuesto, se basaba en su año de creación. En el caso de su título, se puede 
verificar que, para tal efecto, se ocupaba el nombre y apellido de una destacada mujer del contexto histórico nacional. Aunque, también, ello podía obedecer a otras razones más cercanas a la realidad escolar o referidas al apoyo en sus actividades de extensión y cooperación, por mencionar algunas.

Veamos pues, a continuación, de qué manera se estructuró este reconocimiento por medio del análisis de las categorías apriorísticas y emergentes que, en este caso concreto, definimos y encontramos en el estudio.

Partimos, entonces, por identificar las dimensiones y categorías asociadas con el liderazgo de las directoras de escuelas primarias y secundarias públicas que aparecen descritas en el capítulo. Bajo esta perspectiva, se hicieron visibles aquellos estilos de liderazgo educativo y su desarrollo en directoras. Por esta razón, el alto compromiso educativo con la comunidad escolar es el resultado de ciertas prácticas pedagógicas cumplidas por las directoras y de su estrecha vinculación no solo laboral, sino también emocional con el cuerpo docente, así como con los padres y madres, además de los vecinos cercanos y residentes de la ciudad. Es, precisamente, lo que se observa en las directoras escolares descritas en el texto. A modo ilustrativo, cabe decir que tanto en el texto como en algunas de las fotografías están retratadas la directora en solitario o con el grupo de maestras del centro escolar. En el escrito, además, se da a conocer la trayectoria profesional alcanzada, hasta 1927, por la mayor parte ellas. También, se hace alusión de aquellas directoras más reconocidas que ejercieron dicha función en el pasado. Sobre todo, a las que fungieron como primeras directoras en las nacientes escuelas y liceos de niñas. Se observa, asimismo, que solo algunas escuelas y liceos presentan, hasta el año antes expuesto, el listado de maestras que integraban su plantel docente.

Si nos remitimos a la exposición que, en el capítulo, efectúa la profesora Belarmina Puebla en relación a las escuelas superiores de niñas, queda en absoluta evidencia el hecho de que éstas eran dirigidas por maestras normalistas. Se puede decir, por consiguiente, que la base del cargo directivo de las docentes estaba conectada directamente con el nivel formativo alcanzado por ellas. No cabe duda que, a ese respecto, los cursos de perfeccionamiento docente que se realizaban en Chile y en el extranjero ampliaron las posibilidades de las maestras de asumir la función directiva. Fue el caso, por ejemplo, de María Cáceres, quien ejercía como directora de la Escuela Superior de Niñas "Simón Bolívar". Tenía el título de Normalista y, precisamente, había completado su perfeccionamiento de dos años y siete meses de duración en el Teacher's College de la Universidad de Columbia en los Estados Unidos. Este fue financiado por el gobierno de Chile. Por lo demás, en cuanto a la capacitación docente de las directoras correspondientes a las otras cuatro escuelas normales superiores y a una escuela mixta, se verifica que dos de ellas las habían realizado en el país.

Respecto a lo anterior, se puede señalar que las actividades de formación continua realizadas por las tres directoras obedecían a estudios especiales referidos a métodos de enseñanza como el Montessori y la organización del Kindergarten, además de cursos relativos a diversos ámbitos como la cestería, jardinería escolar, gimnasia, cartonaje, pintura, bordado, confección, francés, filosofía y psicología. Todo ello, entregó la posibilidad de integrar nuevos saberes pedagógicos de la Escuela Nueva y prácticas de aula centradas en sus métodos de enseñanza. Por tal razón es que el perfeccionamiento e intereses educativos de 
las directoras, de algún modo u otro, aportó a la renovación de las habituales prácticas de aula en sus escuelas. Como resultado se obtuvo un mayor acercamiento a la reformulación de sus planes de estudio. Valiosos, al respecto, resultaron los cursos impartidos fuera de los ya establecidos en la enseñanza general. Siendo incorporada la enseñanza práctica de la economía del hogar, principalmente. Aunque también se hicieron cursos de decorado, cartonaje y costura, cestería, jardinería y horticultura.

Interesante, además, resulta el trabajo de la directora de la Escuela Mixta No 260 de la Casa de Huérfanos la Normalista Paulina Kurth. Por medio de su trabajo escolar y sus estudios en el método Montessori, pudo dar un interesante y rápido impulso al funcionamiento de un programa oficial de cursos especiales. De esta manera, se dictaron a los y las estudiantes de edades más avanzadas los cursos de confección de juguetes, agricultura, cestería y otros trabajos manuales.

La renovación pedagógica será, entonces, el centro de su gestión directiva. De hecho, se dice que la escuela comenzó a utilizar, a partir de 1925, el método de Decroly con el estudiantado de menor edad. Se hace, de igual modo, mención a las ventajas de éste en su desarrollo intelectual. Cabe, de igual modo, indicar que este centro educativo otorgó un espacio de enseñanza activo y focalizado en el bienestar general de estudiantes con necesidades educativas especiales. Si bien, se utiliza el concepto de retraso mental, se entiende que en el transcurso de esos años existe un amplio desconocimiento de sus sensibilidades y capacidades cognitivas, así como tampoco existe el lenguaje inclusivo. Finalmente, la conexión que la escuela busca otorgar a sus estudiantes con el disfrute de la naturaleza y el respeto al medio ambiente, se convierte en un asunto primordial. Tanto así que se afirma que, la gran parte de las actividades escolares realizadas a diario, se llevan a cabo al aire libre para todos y todas.

Por otro lado, la experiencia previa tanto en el cargo directivo como en la función docente es de suma relevancia para conocer el modo con el que se seleccionaba en la enseñanza primaria a las directoras. En cualquier caso, de todos los centros públicos primarios analizados, solo una directora, con antelación, había ejercido el cargo en dos centros escolares públicos: una escuela elemental y una mixta. Cabe, por tanto, señalar que permaneció en este último centro escolar por dieciocho años en el ejercicio de sus funciones directivas. En contraste con dicha situación, hallamos que el resto de las directoras en funciones no contaba con esa experiencia. Esto significa, a su vez, que se podría haber concedido una mayor valoración tanto a su quehacer docente previo como a su perfeccionamiento. Así, por una parte, creemos que tal premisa está en concordancia con las descripciones que se hacen de las directoras. Y, por otra, observamos que una de las directoras más noveles solo tenía siete años en el cargo, pero destacaba mucho con las innovaciones educativas que se daban en su escuela a través del manejo del eficaz del aprendizaje y del bienestar sanitario del estudiantado.

En cuanto a la interacción afectiva y colaborativa de la directora con las maestras de la escuela, en primera instancia, hay que dejar en total evidencia la alta valoración social que se concedía a las profesionales de la educación. Labor que, lamentablemente, se ha visto bastante menospreciada, sobre todo, en Chile, a partir de las últimas tres décadas del siglo $\mathrm{XX}$ y en lo que va del siglo XXI. 
En la época que revisamos, había una prioridad especial en torno a la permanencia del cuerpo docente en las escuelas y liceos. Así, por ejemplo, se verifica que la mayoría de las maestras de la Escuela Superior No 1, con fecha de 1927, tenían diez años en sus cargos.

Ahora bien, si nos adentramos al apartado referido a la educación secundaria, encontramos que son varias las profesoras de liceos de niñas que escriben sobre el tema. Por lo tanto, la descripción es efectuada mediante una reseña histórica y es redactada por las siguientes profesoras: Fresia Escobar, Ida Corbat, Clarisa Polanco, Aurora Lillo, Elena Arredondo y Amelia Arenas. La profesora de Estado en Castellano, Amanda Labarca, fue la encargada de redactar esta sección inicial, bajo el título de: 'Educación Secundaria. Desarrollo de los liceos de niñas'. En ella, la docente expresa cómo se fue ampliando a cobertura escolar en estos centros educativos.

Sucede, además, que al analizar las características generales de las directoras de estos liceos fiscales de niñas se distingue que eran, para estos seis liceos, en su mayor parte, Normalistas y Profesoras de Estado. Todas ellas, a su vez, habían ejercido labores docentes en distintos centros secundarios. Por lo mismo, la naturaleza de su identidad profesional como docentes y, más tarde, como directoras obedecía a una experiencia construida, tal y como sostiene Reynolds (2002), en base a sus experiencias de género en contextos específicos. De esta forma, todas las directoras eran docentes cuyas prácticas disciplinarias y pedagógicas resultaron ser altamente significativas para sus trayectorias como directoras de centros secundarios. Es así como la identidad profesional es la que define la forma de liderazgo (Cunliffe y Eriksen, 2011). En tal sentido, cabe afirmar que algunas ya habían participado no solo en la fundación, sino también en la dirección de los primeros liceos fiscales. Obviamente, en tal sentido, se les eligió debido a su amplia trayectoria docente en varios liceos femeninos y mixtos del país. La participación de maestras y directoras procedentes de Europa fue vista como un aporte ajustado con el empleo de una educación estricta. Se agradece, por otro lado, la encomiable aportación de connotadas docentes chilenas con respecto al fomento y aumento de la cobertura escolar para niñas y jóvenes.

En lo que atañe y como es sabido, la gestión directiva y pedagógica del centro escolar debe ir acompañada de un liderazgo educativo capaz de impactar indirectamente el aprendizaje estudiantil. Más aún, cuando a partir de ello, se hace patente intervención específica y positiva sobre el clima de la escuela (MacNeil, Prater y Busch, 2009). Lo planteado implica, además, tener en cuenta el sentido de comunidad por el cual transita toda cultura escolar. Esto, porque, influye de una manera profunda y continua en la convivencia, así como en el clima escolar. En suma, tales planteamientos actuales disponen, sin duda, en nuestra opinión, de valiosas directrices que potencian el buen desempeño de las prácticas pedagógicas. Por lo que detrás de dichas premisas, podemos trasladar la noción de liderazgo escolar hacia el pasado. Tenemos, en este punto, que decir que nos parece trascendente explorar la orientación seguida por las directoras en sus labores. Es, de este modo, fundamental profundizar en la existencia o ausencia de tipos de liderazgo que guían sus principios hacia el aprendizaje escolar.

Siguiendo esta perspectiva, se hace pertinente indagar cómo las directoras y el cuerpo docente anteponían el trabajo escolar y el aprendizaje de sus educandas como principios básicos de su acción educativa. En este contexto se puede entender que estamos ante una 
respuesta social que, sobre todo, se articula en torno a la implicación educativa de las maestras. Por esto, su colaboración es siempre muy importante, pues es sobre la cual se reafirma la gestión directiva. Téngase en cuenta que, en esos años, la gestión escolar de las directoras se vio afianzada mediante un estilo de liderazgo facilitador. De esta manera, podemos, a modo ilustrativo, reconocer que en el Liceo de Niñas № 2 "Antonia Salas de Errázuriz", se utilizaban conceptos como fidelidad y continuidad para hacer notar socialmente a su cuerpo docente. De hecho, en el siguiente párrafo, se afirma:

Ese espíritu de continuidad que va contagiando a todas las profesoras llamadas al Liceo es uno de los factores más poderosos, de su prestigio, explica su tradición de seriedad, de disciplina, que encauza los ímpetus de la juventud sin anular su naciente personalidad; es la clave de su constante aspiración hacia el mayor rendimiento de los comunes esfuerzos (Corbat, 1928, p. 233).

Es así como esta cita deja ver la idea de que el buen desempeño y el éxito del centro escolar trae aparejado el prestigio social. Por medio de esto, se hace hincapié en todo el alcance formativo que tenía el profesorado en la sociedad. El caso es que, en este contexto, la tarea educativa poseía una alta valoración social, la cual, claro está, se definía en relación directa con la intervención positiva de su entorno social.

Como vemos, esas acciones son las que se relacionan con la gestión directiva, lo cual, asimismo, trae consigo un liderazgo situado en el aprecio por los demás. Aquí el vínculo cooperativo envuelve un compromiso bastante fuerte entre las maestras y la directora. Dado que con éstas se produce la expansión de la cobertura escolar y la formación específica o diferenciada para niñas y jóvenes. Desde luego, atendiendo los intereses y capacitaciones educativas de maestras y directoras.

Otra cuestión muy importante hace referencia a las relaciones de apertura de la escuela o liceo con padres, madres y vecinos. De esta forma, se pretendía aproximar el colegio a la sociedad a través de actividades abiertas, tales como: conferencias, exposiciones, celebraciones de aniversario, festejo del día de la madre, actos cívicos y veladas literarias o artísticas. Con respecto al vecindario, la intervención escolar se focalizaba en la educación maternal y en la cantina escolar, desde las cuales prestaban ayuda profesoras, directoras y vecinos de la localidad. Esta función de vinculación con el medio social se aprecia también en otras actividades como: las visitas de profesoras junto con estudiantes secundarias a algunas escuelas y liceos vecinos, la entrega del desayuno escolar liderado por estudiantes secundarias a una escuela de niñas. Hay que sumar a lo anterior, las campañas de ayuda escolar que hacían las estudiantes secundarias en apoyo a los damnificados por terremotos en distintas partes del país.

De acuerdo con lo revisado, podemos ver que el compromiso social está muy presente la cultura escolar de la época. Ello se vuelve especialmente evidente en la categoría que definimos como iniciativas y esfuerzo de maestras y/o directoras en el mejoramiento del bienestar escolar. Por citar algunos ejemplos, a saber: a) el constante y desinteresado aporte monetario de maestras y directoras para conseguir más avances en el aprendizaje y en la atención sanitaria o social de sus educandas, b) las reuniones docentes referidas al intercambio de ideas y a la organización anticipada de una multiplicidad de actividades

No 9, 2021. Página $\mid 140$ 
escolares como el aniversario nacional, c) las iniciativas de cooperación de las maestras mediante el uso de su tiempo más allá del horario escolar, las que, de hecho, se concretan con la creación de bibliotecas y ollas infantiles.

Dentro del ambiente cultural de los centros de formación femenina del país, aparecen mencionadas las actividades culturales y de confraternidad con países europeos y latinoamericanos. Cabe destacar, en este aspecto, la notoriedad alcanzada por la Escuela Superior de Niñas "Simón Bolívar". Se visualiza, en ella, el gran acercamiento establecido entre escuelas fiscales de Venezuela y Chile.

En el mismo sentido, se manifiesta que las estudiantes del Liceo N¹ "Javiera Carrera", escribieron cartas a sus símiles en Suiza, Estados Unidos, Rumania y Dinamarca. Por su parte, tanto escuelas como liceos femeninos ubicados en Santiago recibieron la visita de autoridades y ex autoridades de Bolivia, Colombia, Ecuador y Venezuela.

Los puntos anteriores nos permiten ilustrar la realidad escolar que reviste la acción directiva que se configuran mediante su liderazgo. Como hemos podido comprobar, esto se apoya en su alta vocación a partir de su compromiso social. De esta manera, lo que se exhibe, en este caso, es el esfuerzo de maestras y directoras por conseguir en sus educandas un aprendizaje para la vida. En efecto, su bienestar presente y futuro será reforzado por las acciones educativas de ambas. Ejemplo de lo expresado es el sentido valórico y el enfoque maternal que, especialmente, envuelven a la cultura escolar en la educación primaria. Destacamos, entonces, el enfoque maternal que declara la profesora Puebla: "la educación primaria de los niños debiera estar a cargo de maestras, porque ellas pueden, en parte, reemplazar a la madre, realizando de este modo el ideal de la escuela maternal" (1928, p. 120).

Una situación distinta ocurría con las profesoras de Estado que ejercían docencia en liceos fiscales femeninos. De ahí que en su quehacer pedagógico se disponga en torno a la importancia de la disciplina en la instrucción de sus estudiantes, pero al mismo tiempo conceda espacio a la apropiación de aquellos saberes teóricos necesarios para la rendición exitosa de exámenes. Por supuesto, también tenían cabida los saberes prácticos y las actividades sociales o artísticas, entre otras. En tal sentido, queda de manifiesto que, para maestras y directoras, la formación integral de niñas y jóvenes constituyó un asunto fundamental. A pesar de los múltiples problemas de financiamiento escolar, existía en el cuerpo docente y en las directoras una actitud positiva para encarar tales dificultades.

Por todo esto, podemos decir que, las iniciativas escolares de formación de niñas y jóvenes lideradas por las directoras y maestras, partieron de la premisa de que la incorporación de la mujer en el sistema escolar tendría un impacto trascendente para el progreso del país.

\section{Conclusiones}

En este trabajo se pudo comprobar cómo a partir de la Conmemoración del Cincuentenario del Decreto Amunátegui, adquirió importancia el someter a revisión el esfuerzo de las mujeres por conseguir un espacio en el ámbito público y en el desarrollo productivo del país. Todo esto aparecerá, como hemos dicho, expresado en el libro Actividades femeninas en 
Chile (1928). Allí, se habla y da énfasis a la trascendencia educativa que se le otorga a la formación femenina. En lo que concierne a esto último, podemos decir que tanto la educación primaria como secundaria, posibilitaron, de igual modo, la construcción de experiencias significativas en la gestión educativa y en el liderazgo escolar de sus directoras.

Comprobamos que las directoras de centros escolares primarios y secundarios solían recurrir al cuerpo docente para situar y dar permanencia en el tiempo a las múltiples actividades que se efectuaban con sus educandas. Se puede, en tal sentido, hablar de un liderazgo facilitador que se ajusta plenamente con los estilos de liderazgo educativo demostrados en su acción directiva. A partir de ello, pudimos observar que la experiencia docente y directiva previa, así como la permanencia en el cargo son los factores que impactaron positivamente en su labor escolar. Sin duda, su vocación y compromiso, aportaron a consolidar el sentido de pertenencia de maestras, estudiantes, padres, madres y vecindario con el centro escolar.

De acuerdo con el análisis de las actividades escolares y sus significados, queda en absoluta evidencia que las directoras estaban muy interesadas, según fuese el caso, en conseguir o mantener altos niveles de aprendizaje escolar. Como pudimos comprobar, algunas de ellas, integraron sus capacidades y sus estudios en el avance escolar del estudiantado. Así, por ejemplo, algunas de las propuestas de la Escuela Nueva aparecen en sus innovaciones escolares.

Detrás de todo este liderazgo y gestión escolar está, igualmente, presente la intervención del plan de estudio. Su interés no sólo se centró en lo académico, sino que también se ampliaron las actividades de desarrollo personal. Las directoras también estuvieron dispuestas a mantener buenas relaciones con padres, madres y vecinos. De este modo, la escuela o liceo se dispuso como una institución vinculada, primordialmente, con la comunidad local o vecinal. Las actividades como actos cívicos, conmemoraciones asociadas al nacionalismo e intervenciones de ayuda social, sin duda, ampliaron el aprecio que la comunidad otorgó a dichos centros educativos.

Respecto a su visión de la disciplina escolar, cabría aquí, a lo mejor, tener en cuenta el planteamiento de Edwards (2000) sobre el papel público y privado de carácter ambivalente que, de forma permanente, conflictuaba a las directoras. Es decir, por un lado, tener que actuar como una figura pública paternal y autoritaria. Y, por otro, como una figura maternal en el ámbito privado de la escuela y en su ambiente familiar. Creemos que ambas dimensiones, de algún modo u otro, se dieron en las directoras durante el periodo estudiado. No obstante, consideramos que, en este sentido, aún faltan más antecedentes.

La trascendencia de la figura de la directora escolar y su impacto en el ámbito público, sin duda alguna, se torna evidente en el periodo considerado entre 1877 y 1927. Así, es posible comprender la real dimensión de sus aportes como un asunto que engloba la feminización de la educación, cuestión que se sostiene en el alto compromiso pedagógico y social de estas primeras directoras y maestras.

\section{Referencias}


Actividades femeninas en Chile (1928). Santiago de Chile: Imprenta y Litografía La ilustración.

Bazoret, E. (2006). El valor histórico del pituto: clase media, integración y diferenciación social en Chile. Revista de Sociología de la Universidad de Chile, 20, 69-96.

Corbat, I. (1928). Liceo de Niñas "Antonia Salas de Errázuriz" No 2. En Actividades femeninas en Chile (pp. 224-236). Santiago de Chile: Imprenta y Litografía La ilustración.

Edwards, E. (2000). Women principals, 1900-1926: gender and power. History of Education, 29 (5), 405-414.

Cunliffe, A. L. \& Eriksen, M. (2011). Relational leadership. Human Relations, 64 (11), 1425-1449. https://doi.org/10.1177/0018726711418388

Fennell, H. A. (2008). Walking a Fine Balance: The Life History of a Woman Principal. Journal of Women in Educational Leadership, 52. http://digitalcommons.unl.edu/jwel/52.

Growe, R. \& Montgomery, P. (2000). Women and the leadership paradigm: Bridging the gender gap. National Forum Journal, 17E, 1-7.

Labarca, A. (1928). Desarrollo de los liceos de niñas. En Actividades femeninas en Chile (pp. 192-207). Santiago de Chile: Imprenta y Litografía La ilustración.

Little, N. (1983-1984). Why women the best principals. The High School Journal, 67 (2), 77-80.

MacNeil, A. J., Prater, D. L. y Busch, S. (2009). The effects of school culture and clima on student achievement. International Journal of Leadership in Education, 12 (1), 7384, DOI: 10.1080/13603120701576241

Nuñez Prieto, I. (2007). La profesión docente en Chile: Saberes e identidades en su historia. Revista Pensamiento Educativo, 41 (2), 149-164.

Ojeda Laso, M. E. (1993). La fundación de los primeros liceos fiscales femeninos en Chile 1891-1912. Tesis para optar al grado de Licenciado en Historia. Pontifica Universidad Católica de Chile.

Reynolds, C. (2002). Women and School Leadership: International Perspectives. Albany, New York: State University of New York.

Sánchez, K. (2006). El ingreso de la mujer chilena a la universidad y los cambios en la costumbre por medio de la ley 1872-1877. Historia, 39 (2), 497-529. 
Vicuña Domínguez, P. (2012). Muchachitas liceanas: la educación y la educanda del liceo fiscal femenino en Chile, 1890-1930. Tesis para optar al grado de Magíster en Estudios Latinoamericanos. Universidad de Chile. 